\title{
Implications of Allee effects for fisheries management in a changing climate: evidence from Atlantic cod
}

\author{
Anna-Marie Winter, ${ }^{1,3}$ Andries Richter, ${ }^{1,2}$ And Anne Maria Eikeset ${ }^{1}$ \\ ${ }^{1}$ Department of Biosciences, Centre for Ecological and Evolutionary Synthesis, University of Oslo, Oslo N-0316 Norway \\ ${ }^{2}$ Environmental Economics and Natural Resources Group, Sub-Department of Economics, Wageningen University, Wageningen 6700 \\ EW The Netherlands
}

Citation: Winter, A.-M., A. Richter, and A. D. Eikeset. 2020. Implications of Allee effects for fisheries management in a changing climate: evidence from Atlantic cod. Ecological Applications 30(1):e01994. 10.1002/eap.1994

\begin{abstract}
There are concerns that increasing anthropogenic stressors can cause catastrophic transitions in ecosystems. Such shifts have large social, economic, and ecological consequences and therefore have important management implications. A potential mechanism behind these regime shifts is the Allee effect, which describes the decline in realized per capita growth rate at small population density. With an age-structured population model for Atlantic cod, Gadus morhua, we illustrate how interactions between human-induced stressors, such as fishing and climate change, can worsen the impact of an Allee effect on populations by promoting hysteresis. Therefore, the risk of population collapse and recovery failure is exacerbated and the success of preventing and reverting collapse depends on the climate regime. We find that, in presence of the Allee effect, a fishing moratorium is only sufficient for recovery when sea surface temperature rise remains within $2^{\circ} \mathrm{C}$ and fishing is restricted within $10 \mathrm{yrs}$. If sea surface temperature rises beyond $2^{\circ} \mathrm{C}$, even immediate banning of fishing is not sufficient to guarantee recovery. If fishing is not fully banned and a residual fishing pressure remains, the probability of recovery is further decreased, also in the absence of an Allee effect. The results underscore the decisive role of Allee effects for the management of depleted populations in an increasingly human-dominated world. Once the population collapses and its growth rate is suppressed, rebuilding measures will be squandered and collapse will very likely be irreversible. We therefore emphasize the need for proactive management involving precautionary, adaptive measures and reference points. Our studies shows that climate change has the potential to strengthen Allee effects, which could increasingly challenge fisheries management.
\end{abstract}

Key words: Allee effect; Atlantic cod; climate; collapse; fisheries management; hysteresis; marginal effect; proactive management; recovery; regime shift; resilience; tipping points.

\section{INTRODUCTION}

Ecological regime shifts describe the abrupt and persistent change of the community structure that involves multiple variables and key species (Scheffer et al. 2001, Scheffer and Carpenter 2003, Conversi et al. 2015). A potential population ecological mechanism that can lead to a regime shift is the Allee effect (Jiang and Shi 2010, Dai et al. 2012, Dakos et al. 2012). A demographic Allee effect emerges if the realized per capita population growth rate ( $r_{\text {realized; }}$ a metric of average individual fitness accounting for density dependence) reduces with declines in population abundance (Courchamp et al. 1999, Hutchings 2015). If the Allee effect is strong, there is a critical threshold in population density or size (the Allee threshold), below which $r_{\text {realized }}$ drops below zero. In deterministic settings, this causes bistability and the

Manuscript received 29 January 2019; revised 13 July 2019; accepted 25 July 2019. Corresponding Editor: Andrew Rypel.

${ }^{3}$ E-mail: winter.annamarie@gmail.com population will go extinct below the Allee threshold (Berec et al. 2007, Courchamp et al. 2008).

In depleted fish populations, the Allee effect, also called depensation in fisheries ecology, has long been suggested as an explanation for the observed lack of recovery despite substantial fishing reductions (Hutchings 2001, 2015). An iconic example is the collapse of Atlantic cod, Gadus morhua, off the coast of Canada in 1992. Biomass levels declined by $99.9 \%$ (Hutchings and Reynolds 2004) and have not recovered since, despite a commercial fishing moratorium.

Even though marine fishes are one of the most data rich taxonomic groups, approaches to study Allee effects have been limited by a paucity of data at low abundance levels and the difficulty of performing appropriate experimental studies. As a result, there remains a great deal of uncertainty surrounding the prevalence of Allee effects in marine fishes (Myers et al. 1995, Liermann and Hilborn 1997, Gregory et al. 2010). Yet, Allee effects have been suggested for various marine fish such as Atlantic herring, Clupea harengus (Saha et al. 2013, 
Perälä and Kuparinen 2017), shallow-water cape hake, Merluccius capensis (Vergnon et al. 2008), and Pacific salmon, Oncorhynchus spp. (Liermann and Hilborn 2001, Chen et al. 2002), with empirical evidence arguably strongest for Atlantic cod (Rowe et al. 2004, Keith and Hutchings 2012a,b) .

Suggested mechanisms for an Allee effect in marine fish are related to difficulties in finding mates (Rowe et al. 2004), reduced antipredator vigilance due to a smaller school size (Clark 1974, Saether et al. 1996), lowered egg fertilization rate, and decreased genetic variation among offspring (Rowe and Hutchings 2003, Courchamp et al. 2008). Possible Allee effect mechanisms in Atlantic cod include increased predation on adult fish (Swain and Chouinard 2008, Kuparinen and Hutchings 2014, Swain and Benoit 2015) and altered food webs (Walters and Kitchell 2001, Frank et al. 2011).

The recent IPCC report highlights the increased risk to fisheries as global warming reaches beyond $1.5^{\circ} \mathrm{C}$ (IPCC 2018). Climate change has been implicated in large-scale marine regime shifts (Hare and Mantua 2000, Parsons and Lear 2001, Benson and Trites 2002, Beaugrand 2004, Lees et al. 2006, Beaugrand et al. 2008, Möllmann and Diekmann 2012, Conversi et al. 2015, Rocha et al. 2015) and these shifts are likely to increase in frequency. In Atlantic cod, climate change is found to have a negative effect on recruitment for stocks located at the southern end of the species range (Drinkwater 2005, Stige et al. 2006). In the North Atlantic Ocean, both increasing seasonal temperature variability and higher average temperatures are expected (Taboada and Anadon 2012, IPCC 2013, Pörtner et al. 2014).

While both climate change and the Allee effect have been at the origin of regime shifts, it is unclear how the combination of climate change and the Allee effect impacts populations. Environmental variability can decrease population resilience to fishing and increase uncertainty of recovery, especially if recruitment is compromised by an Allee effect (Dennis 2002). Considering a density-independent effect of temperature on recruitment, increasing temperatures may reduce per capita growth rate and shift the Allee threshold to higher biomasses (see also Allee effect variability type I in Walter et al. [2017]). As a result, the depressed per capita growth rate could have unforeseen consequences for fishing activities.

Successful fishery management strategies must account for the potential interaction between climate and an Allee effect. Less favorable climate reduces the maximum fishing pressure the population can withstand and the population collapses at unanticipated high biomass levels, which requires more conservative reference points (Fig. 1a). The Allee effect imposes a concrete time frame where fishing restrictions are sufficient to prevent collapse, and this time frame narrows with increasing temperature. Further, to recover the population it is not sufficient to reduce the fishing pressure to pre-collapse levels or even zero. Instead, negative fishing pressure, i.e. re-stocking may be necessary (Fig. 1b), which is usually not possible for wild stocks. This is, because of the bistability that arises with the presence of an Allee threshold, which introduces an unstable equilibrium point, because below it $r_{\text {realized }}$ becomes negative and the population goes extinct. Extinction is a stable equilibrium, which is reinforced by a negative population growth rate. A shift to the lower equilibrium can occur as a result of a shock event and/or slow changes in the underlying variables and internal feedbacks that define the ecological system (Beisner et al. 2003). Once passing the tipping point, attraction to the extinction equilibrium is stronger than attraction to the high biomass equilibrium and extinction becomes very likely if the underlying changes are not immediately halted.

In case of the Allee effect, fishing pressure gradually reduces the interval between the two equilibrium population sizes, with the result that additional pressure from climate change will be more likely to reduce the population to critical numbers and the population will be more vulnerable to extinction (Stephens and Sutherland 1999). Fishing and climate change are human-induced stressors, which jointly reduce the resilience of the population to the impact of an Allee effect, but only fishing pressure can be controlled by managers. Therefore, once the tipping point is passed, a fast fisheries management response is necessary.

The return path between the two stable equilibrium states can be different from the outgoing path, a phenomenon called hysteresis (Beisner et al. 2003). Because once collapsed, there are no or very few individuals left to produce recruitment, even successful attempts to restore the "original" environmental variables may not result in the recovery of the population (Fig. 1b). Increasing temperature shifts the hysteresis region to appear at even lower fishing values.

Incorporating these factors into a precautionary approach to fisheries management remains challenging (Selkoe et al. 2015). Using North Sea cod as a case study, we illustrate how the interaction between fisheries management strategies (fishing pressure, variability in fishing pressure and delayed management action), directed environmental change (increasing temperature and temperature variability), and an Allee effect can impact the population dynamics and recovery of this population. In light of these results, we identify appropriate strategies that incorporate a precautionary approach to fisheries management. While Allee effects in marine systems may have been uncommon in the past, climate change has the potential to strengthen Allee effects, which could increasingly challenge fisheries management.

\section{Material and Methods}

We developed an age-structured model linked with a stock-recruitment function accounting for (1) absence 


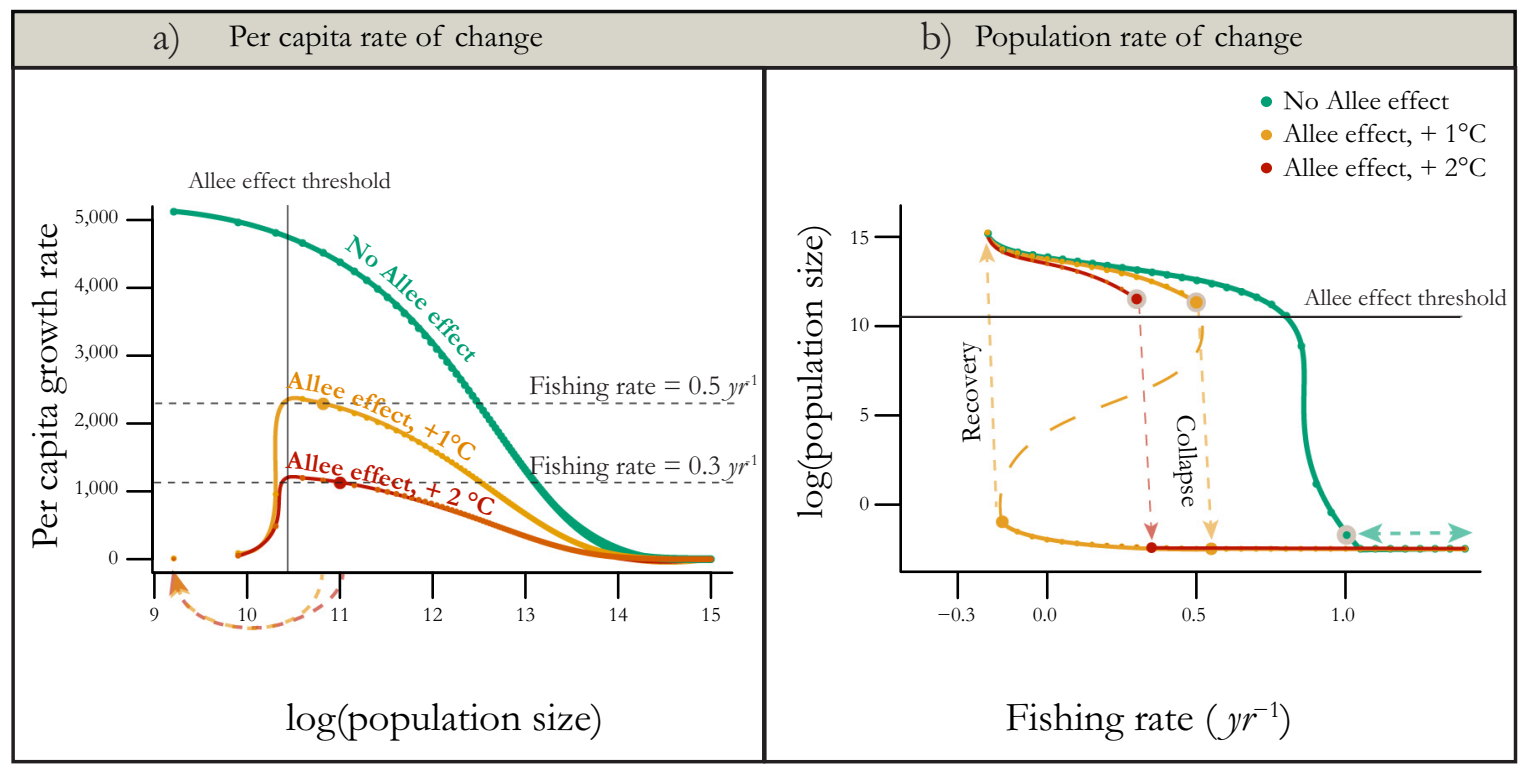

FIG. 1. Reinforcement of hysteresis and a regime shift caused by the interaction between an Allee effect and ocean warming. The green lines indicate the growth rate without an Allee effect and with no ocean warming, the orange lines indicate the growth rate in the presence of an Allee effect and at $+1^{\circ} \mathrm{C}$, and the red lines show the growth rate in presence of an Allee effect and at $+2^{\circ} \mathrm{C}$. (a) The simulated net per capita growth rate as a function of log population size. The strong Allee effect (orange and red lines) introduces an unstable equilibrium point and, in the presence of fishing, the population suddenly collapses at unprecedented high biomass levels. At $+1^{\circ} \mathrm{C}$ and in the presence of an Allee effect, the population can withstand a fishing pressure $\leq 0.5 \mathrm{yr}^{-1}$, at $+2^{\circ} \mathrm{C}$ of $\leq 0.3 \mathrm{yr}^{-1}$. Without an Allee effect, the population declines, but does not suddenly collapse. (b) The simulated net population growth rate as a function of log population size. Temperature strengthens the Allee effect by strengthening hysteresis (orange and red lines) and, as a result, the population trajectory of collapse and recovery differ. Even a reduction of the fishing rate to pre-collapse conditions is not sufficient to recover the population. Increasing temperature shifts the last point before collapse to higher biomasses called "tipping point" in case of a hysteresis and requires higher rebuilding effort. In contrast, the path of collapse and recovery is the same if no Allee effect is present (green line).

and presence of an Allee effect and (2) effects of increasing sea surface temperature, SST. We used Atlantic cod as a case study, as it is a species of high economic and cultural value and for which there is evidence of an Allee effect (Keith and Hutchings 2012b, Cabral et al. 2013). We chose to focus on North Sea cod, where recruitment productivity is found to be negatively affected by increasing temperature (Planque and Fredou 1999, O'Brien et al. 2000, Clark et al. 2003, Pörtner et al. 2008). A $1{ }^{\circ} \mathrm{C}$ increase of SST is predicted to reduce recruitment production by 50\% (Planque and Fredou 1999, Drinkwater 2005). The North Sea cod was MSC certified in 2017, but the most recent assessment found its fishing activity to be unsustainable and biomass levels dropped again below the limit reference point (ICES 2019).

\section{Modeling the Allee effect}

We applied the meta-analysis by Keith and Hutchings (2012b) to Atlantic cod stocks only, to parameterize a recruitment function with an Allee effect and one without an Allee effect. Of the 19 Atlantic cod stocks represented in the Ransom A. Meyers (RAM) legacy database (Ricard et al. 2012; available online) www.ramlegacy.org, we extracted recruit-per-spawner ratios as a proxy for $r_{\text {realized }}$ and fitted a segmented regression to the standardized recruit-per-spawner ratios and spawning stock biomass, SSB (see Appendix S1 for detailed description). The segmented package in $\mathrm{R}$ (Muggeo 2008), was used to estimate a breakpoint at $13.47 \%$ maximum SSB $\left(\mathrm{SSB}_{\mathrm{MAX}}\right)$ with a standard error of 1.7 (Appendix S1: Table S4). The Davies test (Davies 2002) tests for a non-zero difference in the slope parameters of the segmented relationship and was highly significant $(\mathrm{p}<0.01)$. We used the breakpoint as the Allee effect threshold, $\mathrm{SSB}_{\mathrm{AT}}$. $\mathrm{SSB}_{\mathrm{AT}}$ is the biomass threshold below which $r_{\text {realized }}$ starts to decrease. It translates to 34,045.02 metric tons for North Sea cod. For a sensitivity analysis of the breakpoint estimates to the number of stocks considered and the uncertainty level of the individual estimates, see Appendix S1: Tables S4-S6.

For SSB above the Allee effect threshold, we used the same function as for the scenario without an Allee effect. For this, we fitted a Ricker stock-recruitment model (Ricker 1954) by applying linear regression to the standardized recruit-per-spawner ratios of SSB above $40 \%$ $\mathrm{SSB}_{\operatorname{MAX}}$ (Appendix S1: equation S2). For the Allee effect scenario, we extended the stock-recruitment function by an additional parameter, $c$ (Eq. 1), to model the 
observed decline in recruit-per-spawner ratios below the Allee effect threshold (Fig. 2). Even though $r_{\text {realized }}$ drops well below $1(0.4)$ at positive SSB after back-transformation, the modeled Allee effect is considered a strong Allee effect, because of the exponential shape of the stock-recruitment function at low SSB. See Appendix S1, for details on fitting the stock-recruitment functions and an analysis of how our results depend on the values of parameter $c$.

\section{Temperature dependency}

We assumed a linear relation between recruitment and temperature following, e.g., Hilborn and Walters (1992), Clark et al. (2003), Planque et al. (2003), and Ottersen et al. (2013) and because of its easier interpretation when the Allee effect itself is already a nonlinear function. In Appendix S2, we also consider a nonlinear temperature function. We extended the stock-recruitment function by an additional parameter $d$ to account for the linear dependence on sea surface temperature documented by Planque and Fredou (1999) (Eq. 1). Note that $d$ reflects the change in recruitment with a $1{ }^{\circ} \mathrm{C}$ change in the average ambient spawning SST (e.g., $7.95^{\circ} \mathrm{C}$ for the North Sea). We assumed that environmental forcing on recruitment constitutes uncorrelated random white noise (Bjørnstad et al. 2004). Therefore, in our model, $\mathrm{SST}_{t}$ is time varying and a random draw

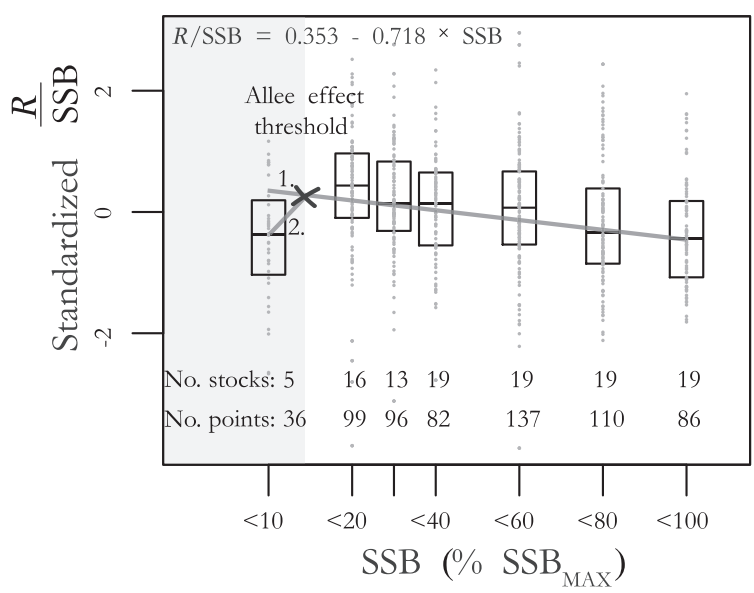

FIG. 2. Box plot of log-transformed, standardized, recruitper-spawner ratios as a function of spawning stock biomass, SSB. Data of 19 Atlantic cod stocks were used. The ratios are a proxy for realized per capita growth rate. Per capita growth rates are categorized to contrast the decline of recruit-perspawner ratios at small SSB range. Gray lines indicate the two contrasting scenarios with and without an Allee effect before the back transformation. For the recruitment function without an Allee effect, a linear Ricker model is fitted (for detailed description, see Appendix S1). The Allee effect scenario was modeled by decreasing the recruit-per-spawner ratio below the Allee effect threshold (star). Box plot components are the median (midline), the first (lower box limit) and third quartile (upper box limit) of the ratios within each category. $R$, recruitment. from a normal distribution with mean $\overline{\mathrm{SST}}$ and variance $\sigma_{\mathrm{SST}}{ }^{2}$. To reflect current climate conditions, $\overline{\mathrm{SST}}$ is zero and $\sigma_{\mathrm{SST}}{ }^{2}$ is equal to the observed variance in North Sea SST, $0.426^{\circ} \mathrm{C}$ (SST was extracted for the years of SSB and was provided by NOAA/OAR/ESRL Physical Sciences Division; available online). ${ }^{4}$

\section{Population dynamics}

Recruitment, $R_{t}$, is dependent on whether $\mathrm{SSB}$ is below or above the Allee effect threshold and given by

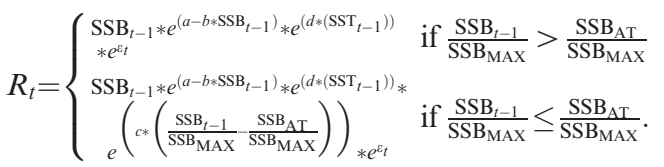

The parameter $\varepsilon_{t}$ captures the interannual recruitment variation and is parameterized using the residuals from the fitted linear regression model (Appendix S1: Eq. S2). The parameter $\varepsilon_{t}$ is a random draw from a normal distribution with mean equal to the residual average of North Sea cod, $\bar{\varepsilon}=1.7$, and standard deviation equal to the standard deviation of the residuals of North Sea cod, $\sigma_{R}$ $=0.63$, which is close to the value documented for marine fish (Beddington and Cooke 1983, Smith and Punt 1998). The exponent $e^{\varepsilon_{t}}$ is lognormally distributed so that annual recruitment production, $R_{t}$, also follows a lognormal distribution (Maunder and Deriso 2003, Methot and Taylor 2011, Devine et al. 2014).

We combined the back-transformed Atlantic cod stock-recruitment functions with a time-discrete cohort model with reproduction and harvesting happening annually at the beginning and end of the year, respectively. The number of individuals in each age class at year $t, N_{\text {age, } t}$, equals cohort abundance of the previous year multiplied by the survival rate (reciprocal of constant natural mortality rate, $M_{\text {age, }}$ and time varying fishing mortality, $\left.F_{t}\right) . F_{t}$ is a random draw from a log-normal distribution with mean equal to the imposed logarithmic fishing pressure, $\bar{F}$, and variance $\sigma_{F}^{2}$ equal to logarithmic variance. The log-normal distribution prevents negative values for $F_{\mathrm{T}}$. In our baseline simulations, we vary $\bar{F}$ and assume variance equal to the observed log variance level in fishing age classes 2-4 (0.210 $\mathrm{yr}^{-1}$; ICES 2016). The realized fishing mortality in the North Sea fluctuates from year to year on average by $6 \%$, but interannual changes up to $27 \%$ have been observed (ICES 2016). All age classes were exposed to the same fishing mortality, except 1-yr-olds, which were considered too small to be caught (ICES 2016). The last age class was treated as a plus group, combining all individuals beyond the age of 11 . The number of individuals in each age class is given by

\footnotetext{
${ }^{4}$ https://www.esrl.noaa.gov/psd/
} 


$$
N_{\text {age }, t}= \begin{cases}R_{t} & \text { if age }=1 \\ N_{\text {age }-1, t-1} * e^{-\left(M_{\text {age }-1}+F_{t-1}\right)} & \text { if } 1<\text { age }<11 \\ N_{11, t}+N_{11, t-1} * e^{-\left(M_{11}+F_{t-1}\right)} & \text { if age }=11^{+} .\end{cases}
$$

When mature, individuals produce recruitment according to the stock-recruitment functions. Spawning stock biomass, $\mathrm{SSB}$, is comprised by

$$
\mathrm{SSB}_{t}=\sum_{\text {age }=1}^{11} \mu_{\text {age }} * w_{\text {age }} * N_{\text {age }, t}
$$

with $\mu_{\text {age }}$ and $w_{\text {age }}$ being the age-specific probability of maturation and age-specific weight (in metric tons). Life history parameters and abundance estimates for North Sea cod were obtained from ICES (ICES 2016) over the time period 1963-2007 (Appendix S1: Table S3). Data on recruitment and SSB were extracted from the RAM legacy database for the time period 1963-2005 (Ricard et al. 2012).

\section{Simulated and predicted probability of collapse and recovery}

We first looked at the simulated probability of collapse and recovery by repeatedly calculating different scenarios and counting the times of collapse and population recovery after depletion, respectively. In a second analysis, we fitted a logistic regression model to the outcome of different simulated scenarios to predict the probability of collapse and recovery. Collapse and recovery scenarios are simulated separately, because they differ in the parameters considered. Each scenario was initialized by simulating population dynamics for $500 \mathrm{yrs}$ without fishing pressure, no temperature increase and without an Allee effect, to find the equilibrium population size. We then simulated different scenarios by exposing the population for $500 \mathrm{yrs}$ to different variables.

For the simulated probability of collapse (Fig. 3a, b), mean SST, SST, was, in each scenario, increased up to $4.5^{\circ} \mathrm{C}$ according to the predictions for year 2100 under the RCP8.5 scenario (IPCC 2014) and predictions from the Hadley Centre for Climate Prediction and Research for year 2099 in the North Sea (Sheppard 2004). Mean fishing pressure, $\bar{F}$, was increased up to $1 \mathrm{yr}^{-1}$, which is well above the level consistent with achieving maximum sustainable yield $\left(F_{\mathrm{MSY}}=0.31 \mathrm{yr}^{-1}\right.$; ICES 2018a). Variance in SST and $F$ remained at the observed level of $0.426^{\circ} \mathrm{C}$ and $0.21 \mathrm{yr}^{-1}$, respectively. Each scenario was repeated 100 times and simulated with and without an Allee effect. For each scenario, the probability of collapse was estimated as the proportion of collapsed population states. A population was defined as collapsed if SSB had at any point of time declined and remained declined below 5\% $\operatorname{SSB}_{\mathrm{MAX}}$ (12,637.35 metric tons; Yletyinen et al. 2018) at least for 8 yrs (one generation). The threshold of $5 \% \mathrm{SSB}_{\mathrm{MAX}}$ was chosen for the reason of being well below the Allee effect threshold of $13.47 \%$ $\mathrm{SSB}_{\operatorname{MAX}}(34,045.02$ metric tons).

For the probability of recovery (Fig. 3c, d), $\bar{F}$ was restricted once biomass fell below the Allee effect threshold to facilitate recovery. At the Allee effect threshold, per capita growth rate is highest, which is comparable to the limit reference point for North Sea cod at which recruitment production is estimated to be above average (ICES 2018a). Extinction can still be prevented at the Allee effect threshold, but it remains unclear under which conditions recovery is still possible. In particular, we were interested in the effect of increasing SST up to $4.5^{\circ} \mathrm{C}$ and the consequences of delayed responses of fisheries management. Scientific assessment, social resistance, and bureaucratic roadblocks tend to delay fishing bans (Hutchings and Reynolds 2004, Agnew et al. 2009, Davies et al. 2009, Brown et al. 2012). We therefore investigated the impact of the fishing moratorium being implemented with different management delays (mgmt. delay), ranging from 0 to $30 \mathrm{yrs}$. We further analyzed the impact of residual fishing pressure (fishing during moratorium), because a zero fishing mortality during recovery is rarely realized. Variance in SST and $F$ remained at observed levels and initial $\bar{F}$ was set to $0.8 \mathrm{yr}^{-1}$ to ensure that biomass would drop below the Allee effect threshold in every scenario. Each scenario was repeated 100 times and with and without an Allee effect. For each scenario, the probability of recovery was estimated as the proportion of recovered population states. The population was classified as recovered if SSB had fallen below the Allee effect threshold at any point of time and subsequently recovered and remained at least for one generation at levels above the Allee effect threshold (for an illustration see Appendix S3: Fig. S1). Thus, cases that declined again after recovery were still considered recovered. However, because $\bar{F}$ was substantially reduced in these cases, there were only very few cases that had declined again after recovery.

For the predicted probability of collapse the presence of an Allee effect (AE; binary) was sampled and the parameters $\overline{\mathrm{SST}}, \bar{F}, \sigma_{\mathrm{SST}^{2}}{ }^{2}, \sigma_{F}^{2}$ were drawn from uniform distributions in a Monte Carlo Analysis. SST varied between $+0^{\circ} \mathrm{C}$ and $+4.5^{\circ} \mathrm{C}, \bar{F}$ varied between 0 and $1.5 \mathrm{yr}^{-1}$. Variance levels were altered with maximum levels according to a doubling of observational values. Fishing variance varied between 0 and $0.297 \mathrm{yr}^{-1}$ and, SST variance varied between $0^{\circ} \mathrm{C}$ and $0.853^{\circ} \mathrm{C} .1500$ scenarios were drawn and a logistic linear regression was fitted with the response variable, $Y_{i}$, equal to the population status (collapsed, not collapsed):

$$
\begin{aligned}
\mathrm{Y}_{i}= & \beta_{0}+\beta_{1} * \mathrm{AE}+\beta_{2}+\overline{\mathrm{SST}}+\beta_{3} * \bar{F}+\beta_{4} * \sigma_{\mathrm{SST}^{2}} \\
& +\beta_{5} * \sigma_{F}{ }^{2}+\varepsilon_{i}
\end{aligned}
$$

For the predicted probability of recovery the presence of an Allee effect was sampled and the parameters SST, $\sigma_{\mathrm{SST}}{ }^{2}, \sigma_{F}^{2}$, mgmt. delay, and fishing during moratorium 

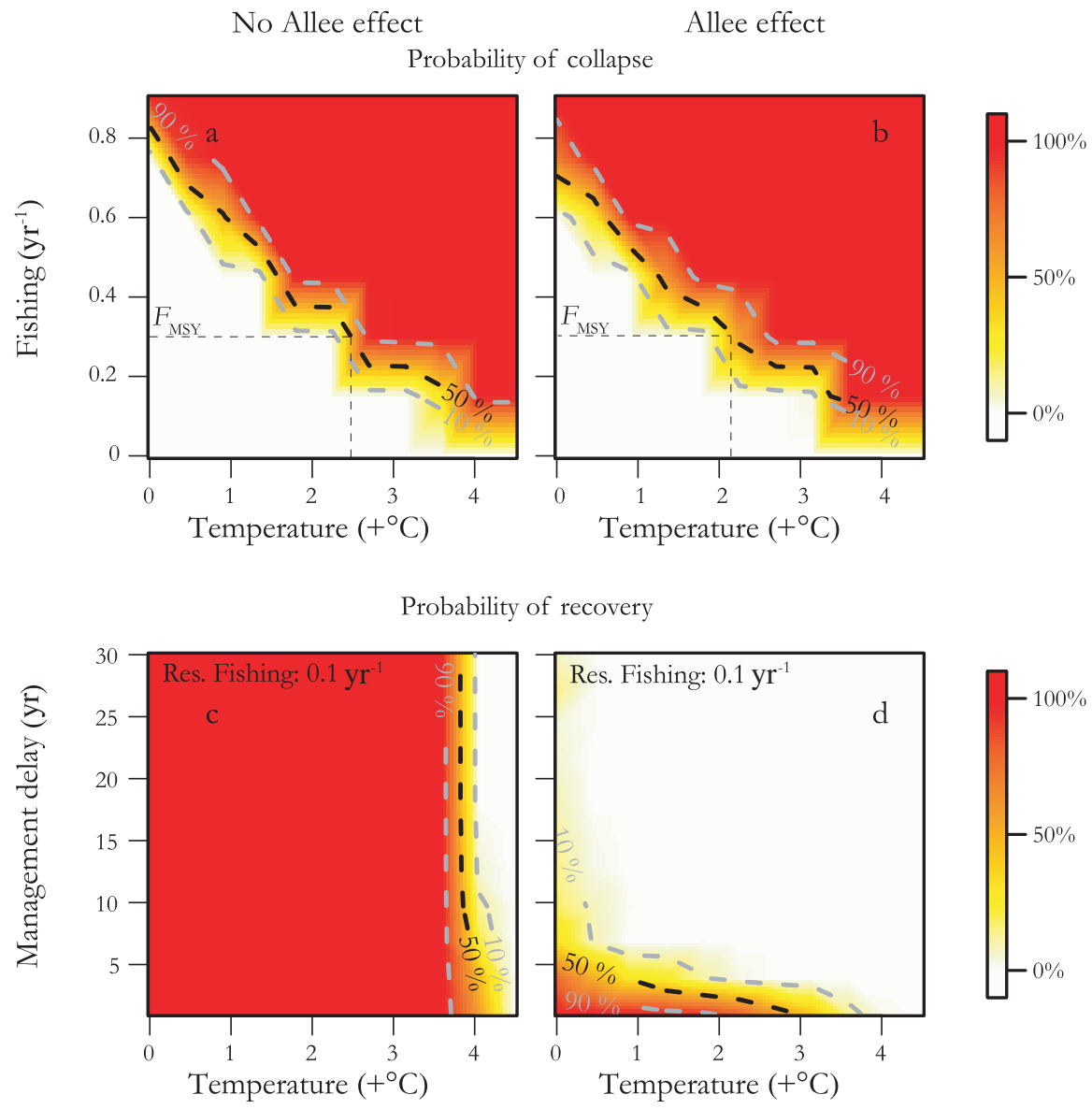

FIG. 3. Simulated probability of collapse and recovery without and in presence of an Allee effect. Broken lines mark the $10 \%$, $50 \%$ and $90 \%$ probability. a) and b) show the probability of collapse at increasing temperature and fishing level. $F_{\text {MSY }}$ indicates the fishing pressure allowing for maximum sustainable yield according to ICES $\left(F_{\mathrm{MSY}}=0.31 \mathrm{yr}^{-1}\right)$. c) and d) show the simulated probability of recovery at increasing temperature level and management delay in imposing a fishing moratorium. A residual fishing pressure of $0.1 \mathrm{yr}^{-1}$ remains despite the moratorium.

were drawn from uniform distributions. For $\overline{\mathrm{SST}}, \bar{F}$, $\sigma_{\mathrm{SST}}^{2}$, and $\sigma_{F}^{2}$ distributions were the same as for the predicted probability of collapse. In addition, the management delay was drawn and varied between 0 and $30 \mathrm{yrs}$ and the residual fishing pressure was sampled and varied between 0 and $0.2 \mathrm{yr}^{-1}$. Initially 3,000 scenarios were drawn, of which 1,500 cases where biomass had dropped below the Allee effect threshold were randomly chosen. Based on these 1,500 cases, a logistic linear regression was fitted with the response variable, $\mathrm{Y}_{i}$, equal to the population status (depleted, depleted and recovered):

$$
\begin{aligned}
\mathrm{Y}_{i}= & \beta_{0}+\beta_{1} * \mathrm{AE}+\beta_{2} * \overline{\mathrm{SST}}+\beta_{3} * \bar{F}+\beta_{4} * \sigma_{\mathrm{SST}^{2}} \\
& +\beta_{5} * \sigma_{F}{ }^{2}+\beta_{6} * \text { mgmt.delay } \\
& +\beta_{7} * \text { fishing during moratorium }+\varepsilon_{i} .
\end{aligned}
$$

For details on model choice, regression analysis, and values of coefficients $\left(\beta_{0}-\beta_{7}\right)$ see Appendix S3.

\section{RESULTS}

\section{Allee effect decreases resilience to fishing pressure and increasing SST}

First, we analyzed how the Allee effect affects the probability of collapse at increasing levels of SST and fishing pressure, $\bar{F}$. In presence of an Allee effect, more population trajectories collapse and the tolerated level of cumulative stress from both fishing pressure and increasing temperature is lower (Fig. 3a, b). Without an increase in temperature and without an Allee effect, a fishing pressure of $0.8 \mathrm{yr}^{-1}$ still keeps the probability of collapse below $50 \%$, whereas in the presence of an Allee effect, $0.8 \mathrm{yr}^{-1}$ would increase the probability of collapse to $90 \%$. Using the $F_{\mathrm{MSY}}$ of $0.31 \mathrm{yr}^{-1}$ naively, in spite of rising temperature levels, will result in a $50 \%$ probability of collapse at $+2.5^{\circ} \mathrm{C}$ in the absence of an Allee effect and at $+2.1^{\circ} \mathrm{C}$ in the presence of an Allee effect. At high levels of both $\bar{F}$ and $\overline{\text { SST }}$, the population collapses irrespective of whether an Allee effect is present. For 
example, when the ambient SST rises to the globally predicted maximum for the North Sea region (Sheppard

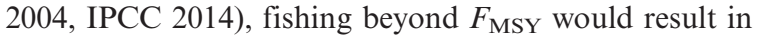
population collapse even in absence of an Allee effect, making the additional, i.e., marginal, impact of an Allee effect disappear.

Analyzing the marginal effects shows when Allee effects matter and are useful to locate tipping points. The increase in SST interacts with the Allee effect by further lowering the already suppressed recruitment production. As a result, the tipping point is moved to lower biomasses, which in turn allows for lower fishing pressure (Fig. 1b). In the region of the tipping point, the impact of the Allee effect on the probability of collapse is highest. Fig. 4 shows the marginal effects of the Allee effect on the probability of collapse. While the probability of collapse increases with increasing level of pressure (increasing number of red cells; Fig. 4), the marginal effects of the Allee effect are highest only at intermediate levels of $\bar{F}$ and $\overline{\mathrm{SST}}$. We find that the Allee effect can increase the probability of collapse up to 88 percentage points and, depending on the cumulative level of stress, the Allee effect can be decisive over whether the population collapses or not (encircled cells; tipping points). For example, at $+3^{\circ} \mathrm{C}$, passing a fishing pressure just above $0.1 \mathrm{yr}^{-1}$ could lead to population collapse in presence of an Allee effect. Therefore, at $+3^{\circ} \mathrm{C}$, the tipping point is between $>0.1 \mathrm{yr}^{-1}$ and $<0.2 \mathrm{yr}^{-1}$. At $+2^{\circ} \mathrm{C}$, the tipping point is between $>F_{\mathrm{MSY}}$ and $<0.45 \mathrm{yr}^{-1}$ (probably closer to $F_{\mathrm{MSY}}$, because of the already elevated marginal effect of 22.6 percentage points). From Fig. 1 we know that in a fully deterministic model the tipping point would be at $0.3 \mathrm{yr}^{-1}$.

In line with Fig. 3, the marginal effects of the Allee effect are minimal at very low stress levels (the population never falls below the Allee effect threshold) and very high cumulative stress levels (the population always collapses anyway). On average, the Allee effect increases the probability of collapse by 5.66 percentage points (Appendix S3: Table S4).

The predicted probability of collapse according to the best fit logistic model is shown in Fig. 6a, b. The fitted model slightly underestimates the probability of collapse in comparison to the simulated probability of collapse in Fig. 3a, b. The fitted model confirms the overall increase of population collapse by the Allee effect ( $\log$ odds increase by 5.6, Appendix S3: Table S3). The regression model shows that temperature, fishing pressure and fishing variance (Appendix S3: Table S3) increase the predicted probability of collapse, and even stronger so in the presence of an Allee effect (marginal effects with Allee effect; Appendix S3: Table S4). We found mean temperature to positively interact with mean fishing pressure. The log odds of fishing increase with increasing mean temperature. Variance of temperature was found to be nonsignificant, while the variance of fishing mortality is highly significant and interacts negatively with mean temperature. Thus, the effect of variance in fishing on the probability of collapse decreases with increasing mean temperature. For example, at $+0^{\circ} \mathrm{C}$, the $\log$ odds of variance in fishing on the probability of collapse are 2.56 , but at $+2^{\circ} \mathrm{C}$, they are only 0.98 .

\section{Allee effect decreases opportunities to prevent and revert population collapse}

As a result of the hysteresis, the trajectory of recovery differs from the collapse trajectory and restoration of pre-collapse conditions (e.g., reducing fishing pressure) may not be sufficient to recover the population. Without an Allee effect, a management delay of implementing a moratorium has no effect on recovery and restricting fishing pressure to $\leq 0.1 \mathrm{yr}^{-1}$ is sufficient to recover the population independent of when fishing is restricted (Fig. 3a, Fig. 6a). Only when SST passes $+3.5^{\circ} \mathrm{C}$, the probability of recovery decreases heavily.

In contrast, the probability of recovery in presence of an Allee effect is heavily dependent on the combination of the management delay and temperature. Generally, higher SST decreases the probability of recovery and the allowable delay in management actions. In the presence of the Allee effect, restricting fishing pressure to $0.1 \mathrm{yr}^{-1}$ is only sufficient for recovery when SST rise remains below $+2^{\circ} \mathrm{C}$ and fishing is restricted within $5 \mathrm{yrs}$ (Fig. 3d). At SST around the globally predicted maximum for the North Sea region (Sheppard 2004, IPCC 2014), even immediate restrictions (no management delay) of fishing are not sufficient to guarantee recovery in the presence of an Allee effect. This is reflected in the interaction term of the best fit logistic regression model for the predicted probability of recovery (Appendix S3: Table S3). Without an Allee effect, the management delay decreases the log odds of the probability of recovery by -0.04 , while the presence of an Allee effect increases the $\log$ odds of the management delay to -0.45 , which restricts recovery significantly (Fig. 3d, Fig. 6d). The fitted model confirms the overall decrease of population recovery by the Allee effect (log odds of probability of recovery decrease by 6.3; Appendix S3: Table S3). The regression model shows that temperature, fishing pressure, the management delay, and residual fishing pressure decrease the predicted probability of recovery (Appendix S3: Table S3). In the absence of an Allee effect, recovery is mainly governed by the combination of SST and the residual fishing mortality (Appendix S3: Table S4).

The Allee effect has a very high impact on the probability of recovery. On average, the Allee effect decreases the probability of recovery by 76.58 percentage points (Appendix S3: Table S4). The marginal effects increase with increasing temperature and management delay (increasing number of red cells; Fig. 5) and are highest at the highest cumulative stress levels. This is, because without the Allee effect, even at the highest pressure levels, the population still recovers (encircled cells, Fig. 5), while the hysteresis of the Allee effect hampers 


\begin{tabular}{|c|c|c|c|c|}
\hline \multicolumn{5}{|c|}{ Marginal effect of Allee effect on probability of collapse } \\
\hline \multirow[t]{2}{*}{ Fishing pressure $\left(\mathrm{yr}^{-1}\right)$} & \multicolumn{4}{|c|}{ Temperature $\left(+{ }^{\circ} \mathrm{C}\right)$} \\
\hline & 1 & 2 & 3 & 4 \\
\hline \multirow[t]{2}{*}{0.1} & 0.0 & 0.0 & 0.0 & 88.0 \\
\hline & $(0.0)$ & $(0.0)$ & $(0.0)$ & $(5.6)$ \\
\hline \multirow[t]{2}{*}{0.2} & 0.0 & 0.0 & 81.8 & 0.0 \\
\hline & $(0.0)$ & $(0.0)$ & $77)$ & $(0.0)$ \\
\hline \multirow{2}{*}{$F_{\mathrm{MSY}}$} & 0.0 & 22.6 & 0.0 & 0.0 \\
\hline & $(0.0)$ & $(8.8)$ & $(0.0)$ & $(0.0)$ \\
\hline \multirow[t]{2}{*}{0.45} & 0.9 & 0.0 & 0.0 & 0.0 \\
\hline & $(0.7)$ & $(0.0)$ & $(0.0)$ & $(0.0)$ \\
\hline \multirow[t]{2}{*}{0.55} & 73.4 & 0.0 & 0.0 & 0.0 \\
\hline & $(10.8)$ & $(0.0)$ & $(0.0)$ & $(0.0)$ \\
\hline
\end{tabular}

FIG. 4. Marginal increase of the probability of collapse associated with the Allee effect at increasing temperature and fishing level. The marginal effects are calculated with the fitted logistic regression model for the probability of collapse. While the probability of collapse increases with increasing cumulative stress level (colored cells), the marginal effect of the Allee effect is highest at intermediate levels of SST and fishing pressure. Depending on the level of cumulative stress, the Allee effect can be decisive over whether the population collapses or not (encircled cells). At these combinations of SST and fishing pressure, a tipping point is likely to be crossed. Estimated standard errors are shown in brackets.

recovery and increasingly so at high SST. Only at temperatures $>+4.5^{\circ} \mathrm{C}$ would the marginal effect decline, because then recovery is also hampered without an Allee effect (Fig. 3c).

Fig. $6 c$, d shows the predicted probability of recovery according to the regression model. It overestimates the probability of recovery. For example, at $+1^{\circ} \mathrm{C}$ the predicted probability of recovery is still $50 \%$ at a management delay of $8 \mathrm{yrs}$ if fishing is restricted to $0.1 \mathrm{yr}^{-1}$, while Fig. $3 c$ suggests at these pressure levels a $0 \%$ probability of recovery. If fishing is fully banned, management has more time to intervene and recovery at $+1^{\circ} \mathrm{C}$ is still likely at a delay of $15 \mathrm{yrs}$ (Fig. 6c). At $+2{ }^{\circ} \mathrm{C}$ however, even a full fishing ban cannot guarantee recovery.

\section{DisCUSSION}

\section{Interaction between climate, fishing, and the Allee effect}

Theory suggests that an Allee effect can cause irreversible regime shifts (Courchamp et al. 2008). We investigated how the presence of an Allee effect, directed SST change and fishery management can interact and synergistically affect the probability of collapse and recovery. Their interaction strongly influences the population responses; for example, if the temperature increase remains $<1^{\circ} \mathrm{C}$, the population can withstand moderate increases in fishing pressure. The Allee effect influences population dynamics primarily when the cumulative effects of SST and fishing pressure are at intermediate levels (Fig. 4). When the cumulative effects are low, the population has a low probability of collapse even with a strong Allee effect, but when the cumulative impact of the stressors is high, the population probability of collapses is high irrespective whether an Allee effect is present. Worryingly, we find that with ongoing climatic changes, we may observe those high levels of cumulative stress within the next century. Our model suggests population collapse for North Sea cod at SST rise $>4^{\circ} \mathrm{C}$, independent of other factors (Fig. 3). This is in line with the recent IPCC report (IPCC 2018), highlighting the increased risk to fisheries if temperatures increase by more than $1.5^{\circ} \mathrm{C}$.

For the Allee effect, which affects recruitment production, warming of the surface waters is crucial because of the planktonic stage of the Atlantic cod larvae and its dependence on plankton prey that occupy surface waters (Sundby 2000, Beaugrand et al. 2003, Clark et al. 2003, Beaugrand and Kirby 2010). Therefore, warming of deeper water layers, which is also slower than in upper layers, will have a minor effect on the interaction with the Allee effect.

There are a number of assumptions underlying this type of simulation study. Estimating the location of the Allee effect threshold as well as the "Allee slope," i.e., the stockrecruitment function below the Allee effect threshold, remains a challenge (Walter et al. 2017). In particular, 
Marginal effect of Allee effect on probability of recovery

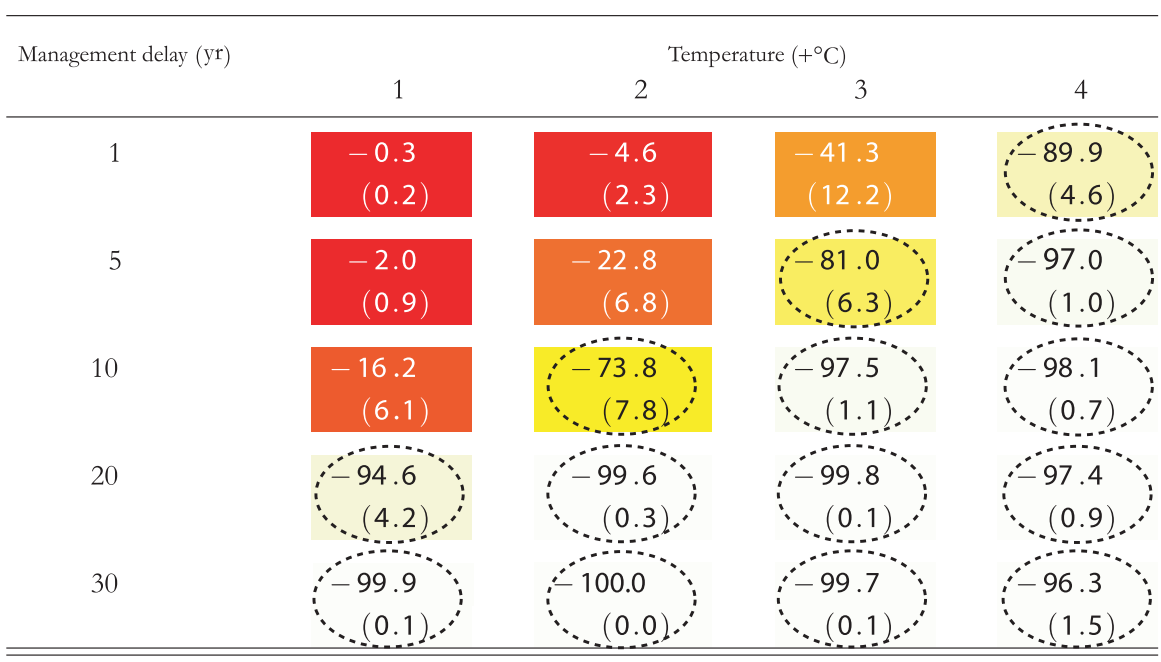

FIG. 5. Marginal decrease of the probability of recovery associated with the Allee effect at increasing temperature and management delay. The marginal effects are calculated with the fitted logistic regression model for the probability of recovery. The probability of recovery for a population with an Allee effect and without is highest at low levels of SST and small management delays (colored cells) and remains high if no Allee effect is present. Therefore, the marginal effect of the Allee effect on the probability of recovery steadily increases with increasing levels of cumulative stress. The presence of the Allee effect can prohibit recovery (encircled cells). The impact of the Allee effect on the probability of recovery is higher than on the probability of collapse. Estimated standard errors are shown in brackets.

changes in recruitment production, survival, food, and predator abundance can alter the temperature and the stock-recruitment relationship (Ottersen et al. 2013, Stige et al. 2013). The sensitivity to temperature increase and the probability of collapse and recovery depends on the Allee effect strength and "Allee slope" (Appendix S1: Table S7, Fig. S4). While the response of Atlantic cod to future warming has been intensively studied, little is known about the mechanisms leading to Allee effects in marine fish (Myers et al. 1995, Liermann and Hilborn 1997, Gregory et al. 2010). Thus, synergistic effects remain unknown and additional experimental research is needed. Nevertheless, unraveling mechanisms at low population abundance and detecting tipping points is often only possible when tipping points have passed and recovery is difficult if not impossible. The collapse of Northern cod is a particularly painful reminder in this regard.

\section{The influence of variability}

As a tipping point is approached, exogenous drivers and natural variation can induce a catastrophic shift to the alternative stable state (Scheffer et al. 2001). In our model, variation in recruitment production, fishing pressure and SST were stochastic elements. Variance in fishing increased the probability of collapse and even stronger in the presence of an Allee effect (Appendix S3: Table S4).

In heavily exploited fish stocks, demographic instability may be elevated through unbalanced targeting of specific age cohorts (Gilpin and Soulé 1986, Lande 1998, Dennis 2002, Hsieh et al. 2006, Anderson et al. 2008, Rouyer et al. 2012). In our simulations, fishing mortality was applied as a non-selective strategy and therefore did not lead to demographic variability. Selective fishing (removing the largest individuals) would elevate population variability and have a detrimental impact on the population.

Variance in temperature was not found to be significant for the predicted probability of collapse or recovery (Appendix S3: Table S3). In our simulations, we assumed temperature to follow a white noise process, causing unusually weak or strong year classes, but rarely leading to a succession of weak or strong year classes, as in the case of autocorrelated noise. If ocean SST is autocorrelated (Vasseur and Yodzis 2004, Rouyer et al. 2010), the succession of weak or strong recruitment years is likely to strengthen the effect of SST variance on recruitment (Morales 1999, Heino et al. 2000, Schwager et al. 2006), which would increase or decrease the risk and consequences of Allee effects.

\section{Incorporating Allee effects in fisheries management}

The interaction between climate and the Allee effect has repercussions for fisheries management. Restoration of the pre-collapse conditions may not lead to recovery due to hysteresis (Fig. 1b). Additionally, climate change is beyond the control of fisheries managers. Our results highlight the need to reduce the stressors unrelated to 
No Allee effect
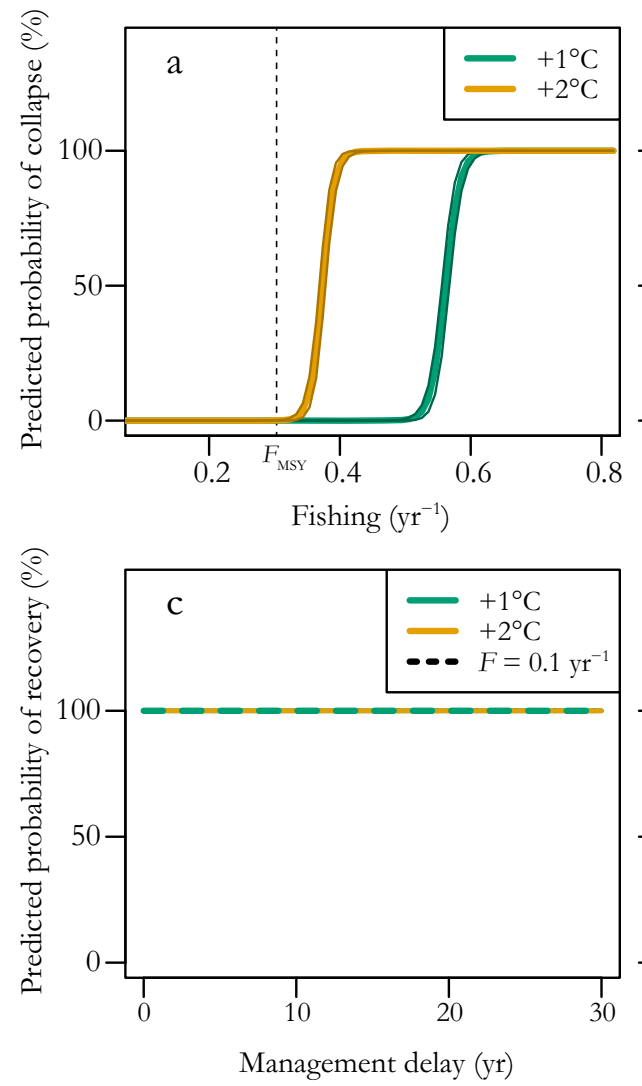

Allee effect
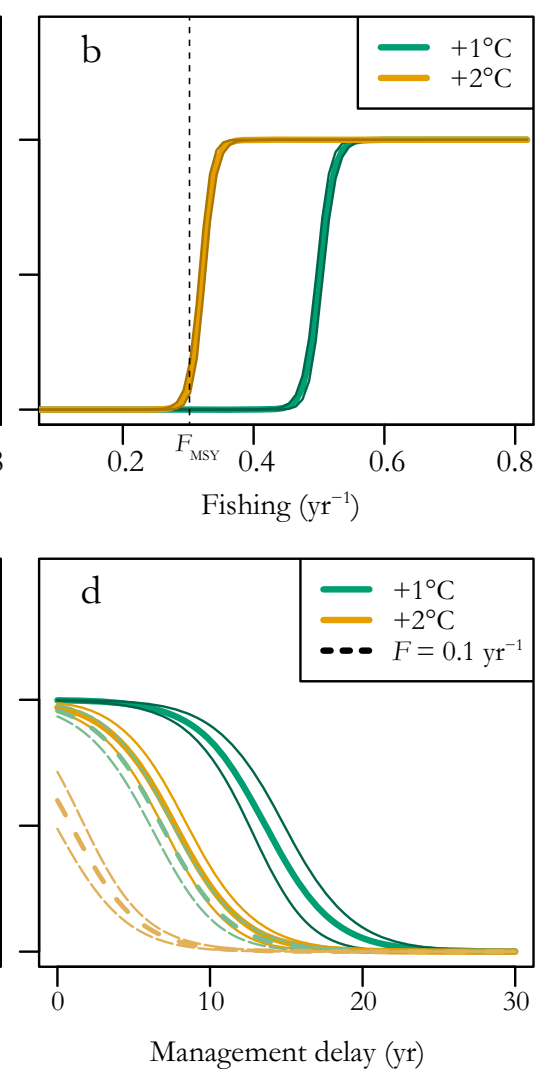

FIG. 6. Predicted probability of collapse and recovery according to the fitted regression models in absence and in presence of an Allee effect. Green lines show the predicted probability at $+1^{\circ} \mathrm{C}$, orange lines show the predicted probability at $+2^{\circ} \mathrm{C}$. $a$ ) and $b$ ) show the predicted probability of collapse at increasing fishing pressure, $c$ ) and $d$ ) show the predicted probability of recovery at an increasing management delay in restricting fishing pressure to zero. Broken lines show the predicted probability of recovery when a residual fishing pressure of $0.1 \mathrm{yr}^{-1}$ is maintained. Thin lines indicate the standard deviation.

climate change, which can be controlled, e.g., fishing mortality (Carpenter et al. 2017, Brander 2018, IPCC 2018). While reductions in fishing mortality are one of the most important factors for recovery (Wakeford et al. 2009), we find that fishing restrictions only lead to recovery when fishery management action is not unduly delayed (i.e. $\leq 10$ yrs), incidental mortality during the moratorium remains as low as possible, and climate change impacts are moderate (i.e. $\leq+2{ }^{\circ} \mathrm{C}$; Fig. $6 \mathrm{~d}$ ).

The implementation of a full fishing moratorium is extremely difficult, especially if the population has a longstanding commercial fishery. Delays in data collection and analysis, communication of science advice, bureaucratic inertia, and social resistance may slow the implementation of the necessary management actions (Hutchings and Reynolds 2004, Brown et al. 2012). Continuation of fishing pressure after a moratorium e.g., through illegal fishing (Agnew et al. 2009) and bycatch (Davies et al. 2009), which is especially a challenge for mixed fisheries such as the North Sea cod fishery, increases the likelihood of reaching a tipping point (Fig. 3d, Fig. 6d). Even in absence of an Allee effect, the combination of high levels of SST and the continuation of high fishing pressure during recovery can be harmful (Appendix S3: Table S4). Similarly, reopening the fishery too soon can impair recovery and nullify recovery efforts. For example, the Northern Cod fishery latest reopening in 2016 took place despite biomass levels remaining below the limit reference point, and the biomass decreased by 30\% again in 2018 (DFO 2018).

Our findings support the notion that a degraded population state is to be avoided because of its increased risk of irreversible collapse (Lande 1998, Kuparinen et al. 2014), especially considering the limited ability of degraded populations to adapt evolutionarily to changed conditions (Kuparinen et al. 2014). Heavy fishing pressure and the alteration of density-dependent regulation at small population size could alter life history traits and recovery behavior after collapse (Fudge and Rose 
2008, Enberg et al. 2009, Eikeset et al. 2016, Nusslé et al. 2016). If changes in life history traits result in depressed $r_{\text {realized, }}$, an Allee effect could even evolve after collapse, when SSB is small.

In fisheries, precautionary measures are usually implemented with limit biomass reference points (ICES 2018a, b), but constant limit reference points may not be precautionary under directed environmental change, for highly variable populations, or when there are delays in management action to reduce fishing pressure (Brown et al. 2012, Dickey-Collas 2016, ICES 2018b). While $F_{\text {MSY }}$ may be optimal under current climatic conditions, this level of fishing has a $50 \%$ probability of collapse when SST increases by $2.5^{\circ} \mathrm{C}$, and leads to certain collapse if SST increases by $3^{\circ} \mathrm{C}$ (Fig. 3a). In the presence of an Allee effect current $F_{\mathrm{MSY}}$ would already lead to certain collapse at an increase in SST of $2.5^{\circ} \mathrm{C}$ (Fig. 3b). Management measures that do not account for time varying productivity are inherently non-precautionary. The current limit reference point for North Sea cod is estimated to yield above-average recruitment based on historic values (ICES 2018a). This is comparable to the Allee effect threshold, which indicates highest per capita production. However, the findings indicate that the validity of these reference points depends heavily on when and how much fishing pressure is reduced and on the productivity baseline.

We defined populations as recovered once biomass reached the limit reference point (Allee effect threshold), but this is only the point when recruitment production is not impaired anymore and could support stock rebuilding. Other modelling results indicate that full rebuilding to the original state in terms of genetic and phenotypic stock structure could be much slower than only biomass recovery alone would suggest (Dunlop et al. 2009, Enberg et al. 2009).

Fisheries management is challenged by the increasing effort towards recovery and rebuilding programs and the need to define appropriate target reference points while productivity baselines are shifting. Adaptive management strategies and regular re-assessments of management reference levels are important, especially when recruitment dynamics and their response to climate change are not well known or difficult to predict (Ottersen et al. 2013, Stige et al. 2013, Munch et al. 2018).

\section{AcKNowledgments}

A. M. Winter, A. Richter, and A. M. Eikeset conceived jointly the study idea. A. M. Winter programmed the model, carried out the simulations, visualized the results, and drafted the manuscript. All authors contributed to the analysis, final writing and revisions of the manuscript. The authors wish to thank Jeffrey A. Hutchings for helpful discussions and the reviewers for valuable suggestions that helped improving the manuscript substantially. The authors acknowledge funding by NordForsk through the projects GreenMAR and TerMARisk (Project Number 81513) and from the Norwegian Research Council under the MARINFORSK program through the project Fishtech (Project Number: 280541) (A. Richter) and through the POLARPROG project STOCKSHIFT (Project Number: 257614).

\section{Literature Cited}

Agnew, D. J., J. Pearce, G. Pramod, T. Peatman, R. Watson, J. R. Beddington, and T. Pitcher. 2009. Estimating the worldwide extent of illegal fishing. PLoS ONE 4:e4570.

Anderson, C. N. K., C. H. Hsieh, S. A. Sandin, R. Hewitt, A. Hollowed, J. Beddington, R. M. May, and G. Sugihara. 2008. Why fishing magnifies fluctuations in fish abundance. Nature 452:835-839.

Beaugrand, G. 2004. The North Sea regime shift: evidence, causes, mechanisms and consequences. Progress in Oceanography 60:245-262.

Beaugrand, G., and R. R. Kirby. 2010. Spatial changes in the sensitivity of Atlantic cod to climate-driven effects in the plankton. Climate Research 41:15-19.

Beaugrand, G., K. M. Brander, J. Alistair Lindley, S. Souissi, and P. C. Reid. 2003. Plankton effect on cod recruitment in the North Sea. Nature 426:661-664.

Beaugrand, G., M. Edwards, K. M. Brander, C. Luczak, and F. Ibanez. 2008. Causes and projections of abrupt climate-driven ecosystem shifts in the North Atlantic. Ecology Letters 11:1157-1168.

Beddington, J. R., and J. G. Cooke. 1983. The potential yield of fish stocks. FAO Fisheries Technical Paper.

Beisner, B., D. Haydon, and K. Cuddington. 2003. Alternative stable states in ecology. Frontiers in Ecology and the Environment 1:376-382.

Benson, A. J., and A. W. Trites. 2002. Ecological effects of regime shifts in the Bering Sea and eastern North Pacific Ocean. Fish and Fisheries 3:95-113.

Berec, L., E. Angulo, and F. Courchamp. 2007. Multiple Allee effects and population management. Trends in Ecology \& Evolution 22:185-191.

Bjørnstad, O. N., R. M. Nisbet, and J. M. Fromentin. 2004. Trends and cohort resonant effects in age-structured populations. Journal of Animal Ecology 73:1157-1167.

Brander, K. M. 2018. Climate change not to blame for cod population decline. Nature Sustainability 1:262-264.

Brown, C. J., E. A. Fulton, H. P. Possingham, and A. J. Richardson. 2012. How long can fisheries management delay action in response to ecosystem and climate change? Ecological Applications 22:298-310.

Cabral, R. B., P. M. Alino, and M. T. Lim. 2013. A coupled stock-recruitment-age-structured model of the North Sea cod under the influence of depensation. Ecological Modelling 253:1-8.

Carpenter, S. R., et al. 2017. Defining a safe operating space for inland recreational fisheries. Fish and Fisheries 18:1150 1160 .

Chen, D. G., J. R. Irvine, and A. J. Cass. 2002. Incorporating Allee effects in fish stock-recruitment models and applications for determining reference points. Canadian Journal of Fisheries and Aquatic Sciences 59:242249.

Clark, C. W. 1974. Possible effects of schooling on the dynamics of exploited fish populations. ICES Journal of Marine Science 36:7-14.

Clark, R. A., C. J. Fox, D. Viner, and M. Livermore. 2003. North Sea cod and climate change - modelling the effects of temperature on population dynamics. Global Change Biology 9:1669-1680.

Conversi, A., et al. 2015. A holistic view of marine regime shifts. Philosophical Transactions of the Royal Society B 370:20130279.

Courchamp, F., T. Clutton-Brock, and B. Grenfell. 1999. Inverse density dependence and the Allee effect. Trends in Ecology \& Evolution 14:405-410. 
Courchamp, F., L. Berec, and J. Gascoigne. 2008. Allee effects in ecology and conservation. Oxford University Press, Oxford, UK.

Dai, L., D. Vorselen, K. S. Korolev, and J. Gore. 2012. Generic indicators for loss of resilience before a tipping point leading to population collapse. Science 336:1175-1177.

Dakos, V., et al. 2012. Methods for detecting early warnings of critical transitions in time series illustrated using simulated ecological data. PLoS ONE 7:e41010.

Davies, R. B. 2002. Hypothesis testing when a nuisance parameter is present only under the alternative: linear model case. Biometrika 89:484-489.

Davies, R. W. D., S. J. Cripps, A. Nickson, and G. Porter. 2009. Defining and estimating global marine fisheries bycatch. Marine Policy 33:661-672.

Dennis, B. 2002. Allee effects in stochastic populations. Oikos 96:389-401.

Devine, J. A., R. D. M. Nash, U. Schaarschmidt, and S. Subbey. 2014. Modelling and forecasting stock-recruitment: current and future perspectives. ICES Journal of Marine Science 71:2307-2322.

DFO. 2018. Technical briefing northern cod. http://ffaw.nf.ca/ sites/ffaw.nf.ca/files/Technical $\% 20$ Briefing $\% 20$ Northern $\% 20$ Cod.pdf. Last accessed 15.09.2019.

Dickey-Collas, M. 2016. The practice of fisheries management Pages 393-409 in C. T. T. Edwards and D. J. Dankel, editors Management science in fisheries: an introduction to simulation-based methods. Routledge, New York, New York, USA.

Drinkwater, K. F. 2005. The response of Atlantic cod (Gadus morhua) to future climate change. ICES Journal of Marine Science 62:1327-1337.

Dunlop, E. S., M. Heino, and U. Dieckmann. 2009. Eco-genetic modeling of contemporary life-history evolution. Ecological Applications 19:1815-1834

Eikeset, A. M., E. S. Dunlop, M. Heino, G. Storvik, N. C. Stenseth, and U. Dieckmann. 2016. Roles of density-dependent growth and life history evolution in accounting for fisheriesinduced trait changes. Proceedings of the National Academy of Sciences USA 113:15030-15035.

Enberg, K., C. Jørgensen, E. S. Dunlop, M. Heino, and U. Dieckmann. 2009. Implications of fisheries-induced evolution for stock rebuilding and recovery. Evolutionary Applications 2:394-414

Frank, K. T., B. Petrie, J. A. D. Fisher, and W. C. Leggett. 2011. Transient dynamics of an altered large marine ecosystem. Nature 477:86-89.

Fudge, S. B., and G. A. Rose. 2008. Life history co-variation in a fishery depleted Atlantic cod stock. Fisheries Research 92:107-113.

Gilpin, M. E., and M. E. Soulé. 1986. Minimum viable populations: processes of species extinction. Pages 19-34 in M. E. Soule, editor. Conservation biology: the science of scarcity and diversity. Sinauer Associates, Sunderland, Massachusetts, USA.

Gregory, S. D., C. J. A. Bradshaw, B. W. Brook, and F. Courchamp. 2010. Limited evidence for the demographic Allee effect from numerous species across taxa. Ecology 91:2151-2161.

Hare, S. R., and N. J. Mantua. 2000. Empirical evidence for North Pacific regime shifts in 1977 and 1989. Progress in Oceanography 47:103-145.

Heino, M., J. Ripa, and V. Kaitala. 2000. Extinction risk under coloured environmental noise. Ecography 23:177-184.

Hilborn, R., and C. J. Walters. 1992. Quantitative fisheries stock assessment: choice, dynamics and uncertainty. Routledge, Chapman \& Hall, London, UK.

Hsieh, C. H., C. S. Reiss, J. R. Hunter, J. R. Beddington, R. M. May, and G. Sugihara. 2006. Fishing elevates variability in the abundance of exploited species. Nature 443:859-862.
Hutchings, J. A. 2001. Influence of population decline, fishing, and spawner variability on the recovery of marine fishes. Journal of Fish Biology 59:306-322.

Hutchings, J. A. 2015. Thresholds for impaired species recovery. Proceedings of the Royal Society B 282:20150654.

Hutchings, J. A., and J. D. Reynolds. 2004. Marine fish population collapses: consequences for recovery and extinction risk. BioScience 54:297-309.

ICES 2016. Report of the Working Group on the Assessment of Demersal Stocks in the North Sea and Skagerrak (WGNSSK), 26 April-5 May 2016, Hamburg, Germany. ICES CM 2016/ ACOM: 14. International Council for the Exploration of the Sea, Copenhagen, Denmark.

ICES. 2018a. Cod (Gadus morhua) in Subarea 4, Division 7.d, and Subdivision 20 (North Sea, eastern English Channel, Skagerrak). ICES Advice on fishing opportunities, catch, and effort. Greater North Sea ecoregion. International Council for the Exploration of the Sea, Copenhagen, Denmark.

ICES. 2018b. ICES advice basis.

ICES 2019. ICES Advice on fishing opportunities, catch, and effort Greater North Sea Ecoregion. ICES Advice on fishing opportunities, catch, and effort. International Council for the Exploration of the Sea, Copenhagen, Denmark.

IPCC 2013. Summary for policymakers. Pages 3-29 in T. F. Stocker, et al., editors. Climate change 2013: the physical science basis. Contribution of working group I to the fifth assessment report of the intergovernmental panel on climate change. IPCC, New York, New York, USA.

IPCC 2014. Climate change 2014: synthesis report. Contribution of Working Groups I, II and III to the Fifth Assessment Report of the Intergovernmental Panel on Climate Change. R. K. Pachauri and L. A. Meyer, editors. Geneva, Switzerland.

IPCC 2018. Impacts of $1.5^{\circ} \mathrm{C}$ global warming on natural and human systems. Pages 1-616 in V. Masson-Delmotte, et al., editors. In Press. Global warming of $1.5^{\circ} \mathrm{C}$. An IPCC Special Report on the impacts of global warming of $1.5^{\circ} \mathrm{C}$ above preindustrial levels and related global greenhouse gas emission pathways, in the context of strengthening the global response to the threat of climate change, sustainable development, and efforts to eradicate poverty.

Jiang, J., and J. Shi. 2010. Bistability dynamics in structured ecological models. Pages 1-357 in S. Cantrell, C. Cosner, and S. Ruan, editors. Spatial ecology. RC Press, Taylor \& Francis Group, London, UK

Keith, D. M., and J. A. Hutchings. 2012a. Corrigendum: population dynamics of marine fishes at low abundance. Canadian Journal of Fisheries and Aquatic Sciences 69:1722-1722.

Keith, D. M., and J. A. Hutchings. 2012b. Population dynamics of marine fishes at low abundance. Canadian Journal of Fisheries and Aquatic Sciences 69:1150-1163.

Kuparinen, A., and J. A. Hutchings. 2014. Increased natural mortality at low abundance can generate an Allee effect in a marine fish. Royal Society Open Science 1:140075.

Kuparinen, A., D. M. Keith, and J. A. Hutchings. 2014. Allee effect and the uncertainty of population recovery. Conservation Biology 28:790-798.

Lande, R. 1998. Demographic stochasticity and Allee effect on a scale with isotropic noise. Oikos 83:353-358.

Lees, K., S. Pitois, C. Scott, C. Frid, and S. Mackinson. 2006. Characterizing regime shifts in the marine environment. Fish and Fisheries 7:104-127.

Liermann, M., and R. Hilborn. 1997. Depensation in fish stocks: a hierarchic Bayesian meta-analysis. Canadian Journal of Fisheries and Aquatic Sciences 54:1976-1984.

Liermann, M., and R. Hilborn. 2001. Depensation: evidence, models and implications. Fish and Fisheries 2:33-58. 
Maunder, M. N., and R. B. Deriso. 2003. Estimation of recruitment in catch-at-age models. Canadian Journal of Fisheries and Aquatic Sciences 60:1204-1216.

Methot, R. D., and I. G. Taylor. 2011. Adjusting for bias due to variability of estimated recruitments in fishery assessment models. Canadian Journal of Fisheries and Aquatic Sciences 68:1744-1760.

Möllmann, C., and R. Diekmann. 2012. Chapter 4: marine ecosystem regime shifts induced by climate and overfishing: a review for the northern hemisphere. Advances in Ecological Research, 47:303-347.

Morales, L. M. 1999. Viability in a pink environment: Why "white noise" models can be dangerous. Ecology Letters 2:228-232.

Muggeo, V. M. R. 2008. segmented: an R Package to Fit Regression Models with Broken-Line Relationships. Statistics in Medicine 22:3055-3071.

Munch, S. B., A. Giron-Nava, and G. Sugihara. 2018. Nonlinear dynamics and noise in fisheries recruitment: a global meta-analysis. Fish and Fisheries 19:964-973.

Myers, R. A., N. J. Barrowman, J. A. Hutchings, and A. A. Rosenberg. 1995. Population dynamics of exploited fish stocks at low population levels. Science 269:1106-1108.

Nusslé, S., A. P. Hendry, and S. M. Carlson. 2016. When should harvest evolution matter to population dynamics? Trends in Ecology \& Evolution 31:500-502.

O'Brien, C. M., C. J. Fox, B. Planque, and J. Casey. 2000. Fisheries: climate variability and North Sea cod. Nature 404:142-142.

Ottersen, G., L. C. Stige, J. M. Durant, K. S. Chan, T. A. Rouyer, K. F. Drinkwater, and S. C. Stenseth. 2013. Temporal shifts in recruitment dynamics of North Atlantic fish stocks: effects of spawning stock and temperature. Marine Ecology Progress Series 480:205-225.

Parsons, L. S., and W. H. Lear. 2001. Climate variability and marine ecosystem impacts: a North Atlantic perspective. Progress in Oceanography 49:167-188.

Perälä, T., and A. Kuparinen. 2017. Detection of Allee effects in marine fishes: analytical biases generated by data availability and model selection. Proceedings of the Royal Society B 284:20171284.

Planque, B., and T. Fredou. 1999. Temperature and the recruitment of Atlantic cod (Gadus morhua). Canadian Journal of Fisheries and Aquatic Sciences 56:2069-2077.

Planque, B., C. J. Fox, M. A. Saunders, and P. Rockett. 2003. On the prediction of short term changes in the recruitment of North Sea cod (Gadus morhua) using statistical temperature forecasts. Scientia Marina 67:211-218.

Pörtner, H. O., C. Bock, R. Knust, G. Lannig, M. Lucassen, F. C. Mark, and F. J. Sartoris. 2008. Cod and climate in a latitudinal cline: physiological analyses of climate effects in marine fishes. Climate Research 37:253-270.

Pörtner, H.-O., et al. 2014. Ocean systems. Pages 411-484 in C. B. Field, V. R. Barros, D. J. Dokken, K. J. Mach, M. D. Mastrandrea, T. E. Bilir et al., editors. Climate change 2014: impacts, adaptation, and vulnerability. Part A: global and sectoral aspects. Contribution of working group II to the fifth assessment report of the intergovernmental panel on climate change. Cambridge University Press, Cambridge, United Kingdom and New York, New York, USA.

Ricard, D., C. Minto, O. P. Jensen, and J. K. Baum. 2012. Examining the knowledge base and status of commercially exploited marine species with the RAM Legacy Stock Assessment Database. Fish and Fisheries 13:380-398.

Ricker, W. E. 1954. Stock and recruitment. Journal of the Fisheries Research Board of Canada 11:559-623.

Rocha, J., J. Yletyinen, R. Biggs, T. Blenckner, and G. Peterson. 2015. Marine regime shifts: drivers and impacts on ecosystems services. Philosophical Transactions of the Royal Society B 370:201302763.

Rouyer, T., J. M. Fromentin, and N. C. Stenseth. 2010. Environmental noise affects the fluctuations of Atlantic large pelagics. Progress in Oceanography 86:267-275.

Rouyer, T., A. Sadykov, J. Ohlberger, and N. C. Stenseth. 2012. Does increasing mortality change the response of fish populations to environmental fluctuations? Ecology Letters 15:658-665.

Rowe, S., and J. A. Hutchings. 2003. Mating systems and the conservation of commercially exploited marine fish. Trends in Ecology \& Evolution 18:567-572.

Rowe, S., J. A. Hutchings, D. Bekkevold, and A. Rakitin. 2004. Depensation, probability of fertilization, and the mating system of Atlantic cod (Gadus morhua L.). ICES Journal of Marine Science 61:1144-1150.

Saether, B. E., T. H. Ringsby, and E. Roskaft. 1996. Life history variation, population processes and priorities in species conservation: towards a reunion of research paradigms. Oikos $77: 217-226$.

Saha, B., A. R. Bhowmick, J. Chattopadhyay, and S. Bhattacharya. 2013. On the evidence of an Allee effect in herring populations and consequences for population survival: a model-based study. Ecological Modelling 250:72-80.

Scheffer, M., and S. R. Carpenter. 2003. Catastrophic regime shifts in ecosystems: linking theory to observation. Trends in Ecology \& Evolution 18:648-656.

Scheffer, M., S. Carpenter, J. A. Foley, C. Folke, and B. Walker. 2001. Catastrophic shifts in ecosystems. Nature 413:591-596.

Schwager, M., K. Johst, and F. Jeltsch. 2006. Does red noise increase or decrease extinction risk? Single extreme events versus series of unfavorable conditions. American Naturalist 167:879-888.

Selkoe, K. A., et al. 2015. Principles for managing marine ecosystems prone to tipping points. Ecosystem Health and Sustainability 1:1-18.

Sheppard, C. 2004. Sea surface temperature 1871-2099 in 14 cells around the United Kingdom. Marine Pollution Bulletin 49:12-16.

Smith, A. D. M., and A. Punt. 1998. Fishery stock assessment models for the 21st century: Combining multiple information sources. Fishery Stock Assessment Models p. 245-286.

Stephens, P. A., and W. J. Sutherland. 1999. Consequences of the Allee effect for behaviour, ecology and conservation. Trends in Ecology \& Evolution 14:401-405.

Stige, L. C., G. Ottersen, K. Brander, K. S. Chan, and N. C. Stenseth. 2006. Cod and climate: effect of the North Atlantic Oscillation on recruitment in the North Atlantic. Marine Ecology Progress Series 325:227-241.

Stige, L. C., M. E. Hunsicker, K. M. Bailey, N. A. Yaragina, and G. L. Hunt. 2013. Predicting fish recruitment from juvenile abundance and environmental indices. Marine Ecology Progress Series 480:245-261.

Sundby, S. 2000. Recruitment of Atlantic cod stocks in relation to temperature and advection of copepod populations. Sarsia 85:277-298.

Swain, D. P., and H. P. Benoit. 2015. Extreme increases in natural mortality prevent recovery of collapsed fish populations in a Northwest Atlantic ecosystem. Marine Ecology Progress Series 519:165-182.

Swain, D. P., and G. A. Chouinard. 2008. Predicted extirpation of the dominant demersal fish in a large marine ecosystem: Atlantic cod (Gadus morhua) in the southern Gulf of St. Lawrence. Canadian Journal of Fisheries and Aquatic Sciences 65:2315-2319.

Taboada, F. G., and R. Anadon. 2012. Patterns of change in sea surface temperature in the North Atlantic during the last three decades: beyond mean trends. Climatic Change 115:419-431. 
Vasseur, D. A., and P. Yodzis. 2004. The color of environmental noise. Ecology 85:1146-1152.

Vergnon, R., Y. J. Shin, and P. Cury. 2008. Cultivation, Allee effect and resilience of large demersal fish populations. Aquatic Living Resources 21:287-295.

Wakeford, R. C., D. J. Agnew, and C. C. Mees. 2009. Review of institutional arrangements and evaluation of factors associated with successful stock recovery plans. Reviews in Fisheries Science 17:190-222.
Walter, J. A., K. L. Grayson, and D. M. Johnson. 2017. Variation in Allee effects: evidence, unknowns, and directions forward. Population Ecology 59:99-107.

Walters, C., and J. F. Kitchell. 2001. Cultivation/depensation effects on juvenile survival and recruitment: implications for the theory of fishing. Canadian Journal of Fisheries and Aquatic Sciences 58:39-50.

Yletyinen, J., et al. 2018. When is a fish stock collapsed? bioRxiv. https://doi.org/10.1101/329979

\section{SUPPORTING INFORMATION}

Additional supporting information may be found online at: http://onlinelibrary.wiley.com/doi/10.1002/eap.1994/full

\section{Data Availability}

All data used in this study were extracted from publicly accessible data bases. No new data were used. Data for North Sea cod was extracted from the publicly available data base provided by ICES (www.ices.dk), sea surface temperature data were provided by the Earth System Research Laboratory, Physical Sciences Division, NOAA (www.esrl.noaa.gov/psd). Spawning stock biomass and recruitment data of other Atlantic cod stocks were taken from the Ransom A. Meyers (RAM) legacy database (www.ramlegacy. org). A summary of the exact parameter values used in the population model is found in the Supporting Information. The R code used in the current study's analyses is available in the Supporting Information (Metadata S1, Data S1) and is directly executable with the attached data file. 